\title{
Utilización de Facebook como canal de comunicación en el sector de la moda: una comparativa de su vertiente dialógica entre las marcas de moda rápida y de lujo
}

\section{Marián Navarro-Beltrá1 \\ Irene García Medina² Susana Miquel-Segarra ${ }^{3}$}

Recibido: 22/01/2019

Aprobado por pares: 22/04/2019
Enviado a pares: 30/01/2019

Aceptado: 08/06/2019

DOI: $10.5294 /$ pacla.2020.23.3.5

Para citar este artículo/to reference this article/para citar este artigo Navarro-Beltrá, M., García Medina, I. y Miquel-Segarra, S. (2020). Utilización de Facebook como canal de comunicación en el sector de la moda: una comparativa de su vertiente dialógica entre las marcas de moda rápida y de lujo. Palabra Clave, 23(3), e2335. https:// doi.org/10.5294/pacla.2020.23.3.5

\section{Resumen}

Las redes sociales, y en concreto Facebook, son frecuentemente utilizadas tanto por la población como por todo tipo de organizaciones. En concreto, las empresas suelen emplear la comunicación digital para crear vínculos emocionales con el usuario. En este sentido, especialmente llamativa resulta la industria de la moda, ya que se trata de un sector en el que se usan con frecuencia las redes sociales. Así, con el propósito de conocer las características de la comunicación digital que se realiza desde el ámbito empresarial, este trabajo se basa en examinar el uso de Facebook por parte de las marcas de moda. Dadas las grandes diferencias que existen dentro de esta

\footnotetext{
$凶$ https://orcid.org/0000-0002-6898-569X. Universidad Católica de Murcia, España. mnavarro2@ucam.edu

https://orcid.org/0000-0003-4424-3357. Glasgow Caledonian University, Escocia. irene.garcia2@gcu.ac.uk

https://orcid.org/0000-0002-0337-7503. Universitat Jaume I, España. smiquel@uji.es
} 
industria, resulta necesario comparar el uso que las marcas de moda rápida y de lujo realizan de esta herramienta de comunicación. Para ello, se lleva a cabo un análisis de contenido de las publicaciones efectuadas entre el 1 de enero y el 30 de junio de 2017 en Facebook por diferentes empresas relacionadas con el ámbito de la moda. Los principales resultados ponen de manifiesto que, pese al interés mostrado por los seguidores de las marcas de moda estudiadas en dialogar, en especial con las de lujo, estas no están aprovechando plenamente las posibilidades de comunicación bidireccional que ofrece Facebook.

\section{Palabras clave (Fuente: tesauro de la Unesco)}

Internet; redes sociales; medios sociales; Facebook; moda; análisis de contenido; contenido de la programación. 


\section{Using Facebook as a Communication Channel in the Fashion Industry: A Comparison of its Dialogical Side between Fast and Luxury Fashion Brands}

\section{Abstract}

Both people and all kinds of organizations frequently use social media, especially Facebook. Companies in particular resort to digital communication to create emotional bonds with users, which is the case of the fashion industry. To identify the features of digital communication in business, this paper examines the use of Facebook by fashion brands. Given the substantial differences within this industry, it is necessary to compare how fast and luxury fashion brands operate this networking tool. For this, content analysis is performed on Facebook posts published by various fashion-related companies between January 1 and June 30, 2017. The main results show that, despite the interest of followers of the studied fashion brands in having a conversation, especially with luxury brands, these are not taking full advantage of the two-way communication possibilities offered by Facebook.

\section{Keywords (Source: Unesco Thesaurus)}

Internet; social networks; social media; Facebook; fashion; content analysis; programme content. 


\section{Utilização do Facebook como canal de comunicação no setor da moda: um estudo comparativo de sua vertente dialógica entre 0 fast-fashion e as marcas de luxo}

\section{Resumo}

As redes sociais, em específico o Facebook, são com frequência utilizadas tanto pela população quanto pelas organizações. As empresas costumam utilizar a comunicação digital para criar vínculos emocionais com o usuário. Nesse sentido, chama a atenção a indústria da moda, já que se trata de um setor em que as redes sociais são usadas de forma constante. Assim, com o objetivo de conhecer as características da comunicação digital realizada a partir do contexto empresarial, este trabalho se baseia em examinar o uso do Facebook pelas marcas de moda. Tendo em vista as grandes diferenças que há nessa indústria, é necessário comparar o uso que as marcas de fastfashion e de luxo realizam dessa ferramenta de comunicação. Para isso, é feita uma análise das publicações entre $1^{\circ}$ de janeiro e 30 de junho de 2017 no Facebook por diferentes empresas do âmbito da moda. Os principais resultados evidenciam que, embora o interesse mostrado pelos seguidores das marcas de moda estudadas em dialogar em especial com as de luxo, estas não estão aproveitando de forma integral as possibilidades de comunicação bidireccional que o Facebook oferece.

\section{Palavras-chave (Fonte: tesauro da Unesco)}

Internet; redes sociais; mídia social; Facebook; moda; análise de conteúdo; conteúdo de programação. 


\section{Introducción}

Según investigaciones previas, el abundante uso de las tecnologías de la información y de la comunicación (TIC) ha transformado todos los ámbitos de la experiencia humana (Acosta, 2012, p. 686). Entre otras cuestiones, la comunicación entre personas e instituciones ha sufrido importantes cambios debido a los avances tecnológicos y a la democratización de su accesibilidad y de su uso, de forma que ahora la comunicación es más amplia y horizontal (García, 2010).

En este sentido, y para ser eficaz, la comunicación digital debe ser interactiva y participativa, pues su objetivo se basa en crear vínculos emocionales entre el usuario y la marca o empresa (Castelló, 2012, p. 67). Así, "la web 2.0 permite que la organización interactúe con sus públicos y con los usuarios, comunicándose a un nivel nuevo, sin limitaciones temporales o espaciales" (Reina, Fernández y Noguer, 2012, p. 123). De esta forma, hoy día se considera que internet es uno de los canales esenciales en la comunicación e interacción de personas, instituciones y empresas (Castelló, 2012, p. 67).

Actualmente, dentro de internet, las redes sociales son utilizadas con gran frecuencia (García, Fernández, Durán y Vélez, 2015, p. 44). Así, se puede afirmar que entre la ciudadanía el grado de penetración de estas herramientas de comunicación va en aumento (Fernández y Díaz-Campo, 2014, p. 181). De hecho, el uso de las redes sociales es cada vez más habitual en la vida cotidiana de las personas de todo el mundo (Phua, Jin \& Kim, 2017, p. 412).

En este sentido, las empresas utilizan las redes sociales de manera habitual para comunicarse con sus clientes (García et al., 2015, p. 44). Estas plataformas son idóneas para que la marca nutra, afiance y refuerce los elementos que pueden originar aprecio y complicidad en sus clientes, en especial en aquellos que utilizan habitualmente las redes sociales y se identifican con la marca; esta identificación se materializa con un consumo fiel (Marauri, Pérez y Rodríguez, 2015, p. 136). 
De esta forma, las redes sociales suponen un nuevo modelo de comunicación entre las organizaciones y los ciudadanos basado en la multidireccionalidad y centrado en el compromiso de interactuar, situación que supone ser un usuario proactivo en las comunidades digitales de las que se decide formar parte libremente (Túñez y Sixto, 2011, p. 211). Por tanto, desaparece la tradicional separación entre emisor y receptor, ya que estos roles dejan de ser pasivos y se intercambian continuamente (Aced, 2013, p. 75). Así, una de las principales ventajas de las redes sociales sobre los medios de comunicación más tradicionales (televisión, radio, etc.) es su capacidad para generar una mayor interactividad del usuario (Phua et al., 2017, p. 413).

"Una vez superado el reto de estar en redes sociales, las organizaciones (ya sean empresas, instituciones u organizaciones no gubernamentales) se plantean el cómo hay que estar en las redes sociales y qué hay que hacer en ellas" (Viñarás y Cabezuelo, 2012, p. 89). Así, los profesionales del marketing se encuentran ante el reto de descubrir cómo atraer clientes y conservar la relación que mantienen con ellos a través estas plataformas (Cheung \& Leung, 2016, p. 57).

En este sentido, se puede afirmar que para realizar una gestión de la comunicación con éxito en las redes sociales se deben crear contenidos que interesen a los usuarios más allá de los propios de la organización, mantener un diálogo simétrico y constante que esté comprometido con los intereses de los usuarios y utilizar un lenguaje apropiado (Viñarás y Cabezuelo, 2012, p. 95). De esta forma, los discursos excesivamente corporativos o comerciales no tendrán éxito, ya que las personas no suelen utilizar este tono para comunicarse (Aced, 2013, p. 76). Por tanto, las empresas deben usar un lenguaje fresco, educado, directo pero no agresivo, alejado de un tono institucional y de formalismos, amistoso, coloquial y próximo al internauta, con el propósito de no romper con el discurso social habitual de internet (Viñarás y Cabezuelo, 2012, p. 95).

Dentro de las redes sociales, Facebook se ha convertido en un canal muy popular para que las empresas promocionen sus productos o marcas (Cheung \& Leung, 2016, p. 56), situación que tal vez se pueda explicar por 
la gran cantidad de usuarios y, por tanto, de potenciales clientes que posee. De esta forma, en junio de 2017, Facebook alcanzó los 2000 millones mensuales de usuarios (Nataur, 2017; Tongo, 2017). Así, cabe señalar que en todo el mundo la actividad diaria en Facebook es considerablemente elevada (Pedersen, Naranjo \& Marshall, 2017).

En este sentido, se puede señalar que la filosofía 2.0 en general, y las redes sociales en particular, se ha integrado en todo tipo de instituciones (públicas, privadas, con ánimo de lucro o sin él) (Túñez y Sixto, 2011, p. 211). Sin embargo, el sector de la moda resulta especialmente relevante, ya que sus consumidores recurren cada vez con más frecuencia a internet para investigar sobre productos y tendencias de moda antes de realizar sus compras (Tuunainen \& Rossi, 2002, p. 1596). Así, los estudios sobre el impacto de las redes sociales en la venta minorista de productos de moda establecen que a los consumidores les gusta estar en contacto con este tipo de marcas a través de tales herramientas de comunicación, situación que conlleva que las empresas minoristas de moda se interesen enormemente por las redes sociales (Ertemel \& Ammoura, 2016, p. 82).

Dentro del sector de la moda cabe destacar que, inicialmente, las marcas de lujo dudaron ante la posibilidad de estar presentes en la red al considerar que la accesibilidad de la marca que internet ofrecía a los usuarios podría mermar su imagen de exclusividad (Del Pino y Castelló-Martínez, 2015 , p. 120). Aunque la industria del lujo se suele relacionar especialmente con el ámbito de la moda, no podemos olvidar que existen otros sectores de actividad que también se vinculan con este concepto, a saber: joyería, perfumería y cosmética, accesorios, relojería, automóviles/motos, bebidas alcohólicas, tecnología, inmuebles, mobiliario y decoración, viajes/turismo, cultura y alimentación (Liberal y Sierra, 2016, p. 943).

En general, que el concepto de lujo se asocie con la exclusividad conlleva que sus productos posean un precio elevado, que se utilicen materiales valiosos y habitualmente escasos y que se emplee mano de obra detallada (Torres-Briones, Rojas-Dávila y Cabrera-Jara, 2017, pp. 586-587). En concreto, las empresas relacionadas con la moda de lujo suelen tratar de obtener 
la mejor calidad tanto en el proceso de producción como en sus materiales (Fung \& Choi, 2018, p. 27). Esta situación conlleva que las marcas de lujo no estén al alcance de toda la población principalmente por razones económicas (Costa, 2007, p. 111), de manera que cuando los consumidores adquieren este tipo de bienes esperan conservarlos durante un largo periodo (Torres-Briones et al., 2017, p. 588).

Cabe destacar que las preferencias por el tipo de lujo no son universales. Por ejemplo, algunos perfiles de consumidores (los nuevos millonarios chinos, brasileños, indios o rusos) o en algunas áreas del mundo (los países árabes más ricos) se decantan por un lujo ostentoso, mientras que en otras zonas (como Europa o los Estados Unidos) predomina un lujo más sobrio (Sicard, 2010).

A pesar de las reticencias iniciales de las marcas de moda de lujo por estar presentes en internet, durante la última década este sector ha conseguido implicar a sus usuarios a través de un intenso movimiento de información en las redes sociales (Facebook, Instagram, Twitter, Pinterest, YouTube, etc.), de desarrollar sitios web y de crear aplicaciones móviles (Escobar, 2016, p. 24).

Así, hoy día el marketing digital se ha transformado en una herramienta imprescindible para que las marcas de moda de lujo se comuniquen con sus públicos (González y Plaza, 2017, p. 18). De esta forma, en la actualidad, "prácticamente todas las marcas de lujo cuentan con una estrategia digital definida, incorporando la presencia en redes sociales para interactuar con los usuarios" (Del Pino y Castelló-Martínez, 2015, p. 120). Ante este contexto, las marcas de lujo ya no se preguntan si deben aprovechar la oportunidad digital, sino cómo pueden hacerlo (Remy, Catena \& DurandServoingt, 2015, p. 5).

Pero no solo las marcas de moda de lujo utilizan la comunicación digital. La entrada de prendas semanales en las cadenas y los continuos cambios de colección que caracterizan el fast fashion convierten las TIC en las herramientas perfectas para mantener informados a sus seguidores y recibir feedback (Morales y Morales, 2017, p. 2). 
La moda rápida es una tendencia que se basa en cambiar la oferta de ropa cada pocos días, lo que implica incorporar nuevas colecciones en breves lapsos de tiempo y dejar a un lado las tradicionales temporadas de primavera-verano y otoño-invierno (López, 2012, p. 73). Así, el fast fashion, que trata de reproducir las tendencias de los diseñadores de moda más destacados (Toboso, 2017, p. 3), se caracteriza por tener precios asequibles y una baja calidad en sus acabados y materiales (Nunes y Da Silveira, 2016, p. 60).

Así, para que las marcas de moda rápida puedan disminuir los riesgos de pérdida, mejorar las ventas e incrementar la eficiencia de la producción, necesitan conocer los deseos, los gustos y las necesidades de sus consumidores (Zambon, Busichia, Torres y Galindo, 2017, p. 50, 58). Además, la continua retroalimentación que las empresas reciben en las redes sociales a través de los me gusta y de los comentarios de los usuarios les posibilita evaluar su comunicación (Manikonda et al., 2016).

De esta forma, aunque la utilización de los medios sociales por parte de las organizaciones es una alternativa muy valiosa que permite obtener información y comunicarse con sus públicos, numerosas investigaciones evidencian que muchas empresas todavía no están aprovechando totalmente las oportunidades de interacción que ofrecen y aún utilizan una comunicación unidireccional (Aced y Lalueza, 2016, pp. 136-137).

Ante esta situación, parece relevante continuar obteniendo información sobre este tema y conocer cómo las marcas de moda se comunican con sus seguidores a través de los social media. Especialmente interesante resulta el análisis de Facebook, ya que, como se ha comentado, posee una gran cantidad de usuarios. Además, dentro del sector de la moda destaca la importancia de conocer si existen diferencias entre la comunicación digital efectuada por las marcas de moda rápida y por de lujo. Esta importancia se puede explicar al considerar que este sector se articula en torno a dos industrias claramente diferenciadas (la alta costura y la confección industrial) que suponen grandes desemejanzas en el uso de técnicas, precios, fama y objetivos que concuerdan con una sociedad también dividida en formas de vida, clases y aspiraciones (Lipovetsky, 1996, p. 77). 
Así, el objetivo general de este trabajo se basa en comparar la comunicación que las marcas de moda rápida y las de lujo realizan a través de Facebook. En concreto, se pretende analizar el uso de esta herramienta en relación con las características de las publicaciones, el contenido mostrado y las interacciones que suscitan.

De esta forma, se pretende averiguar la manera en que las organizaciones relacionadas con el ámbito de la moda interactúan con sus públicos a través de una herramienta de comunicación online que ofrece amplias posibilidades para fomentar el diálogo. Por tanto, se trata de descubrir si este tipo de instituciones están aprovechando el potencial comunicativo y dialógico que ofrecen las redes sociales y si existen diferencias en su aprovechamiento en función del tipo de marca (moda rápida o de lujo).

\section{Metodología}

Con la finalidad de alcanzar los objetivos indicados, se recurrió a la metodología cuantitativa y, en concreto, se realizó un análisis de contenido. Específicamente, se examinaron las publicaciones realizadas en Facebook por H\&M, Zara, Ralph Lauren y Hugo Boss. Las dos primeras organizaciones fueron seleccionadas por ser consideradas marcas de moda rápida (Rocha, 2018, p. 110), mientras que Ralph Lauren (Blum, Flores, Vallejo y Sánchez, 2016) y Hugo Boss suelen ser catalogadas como marcas relacionadas con el sector de la moda de lujo (Matthiesen \& Phau, 2010). Estas cuatro instituciones fueron escogidas por ser las únicas pertenecientes a la categoría apparel del ranking The Best 100 Brands 2015 realizado por Interbrand (2015). Con referencia a los perfiles examinados, cabe destacar que se seleccionó el internacional, es decir, si la marca poseía más de una cuenta en Facebook, se eliminaron las que hacían alusión específicamente a determinados países. Además, todos los perfiles analizados contaron con el reconocimiento de ser una cuenta verificada. ${ }^{4}$

4 Las cuentas finalmente analizadas fueron las siguientes: Zara: https://www.facebook.com/pg/Zara/posts/?ref=page _ internal; H\&M: https://www.facebook.com/pg/hm/posts/?ref=page_internal; Ralph Lauren: https://www.facebook.com/pg/RalphLauren/posts/?ref=page_internal; Hugo Boss: https://www.facebook.com/pg/hugoboss/ posts/?ref=page_internal 
Las publicaciones analizadas fueron efectuadas por las marcas señaladas entre el 1 de enero y el 30 de junio de 2017. Este periodo fue escogido porque enero y junio son los meses en los que tienen lugar las semanas de desfiles dedicados a la alta costura (García, 2015). Además, cabe destacar que la recogida de datos tuvo lugar en julio de 2017.

Tras seleccionar los perfiles y las fechas indicadas, se obtuvieron 489 publicaciones: 269 fueron realizadas por marcas de moda rápida (55\%) y 220 por empresas de lujo (45\%), todas fueron codificadas y analizadas para la realización de esta investigación. Con el propósito de llevar a cabo el proceso de codificación, se creó una ficha de análisis compuesta por diversas variables que recogía información sobre la fecha de publicación, el idioma utilizado, las menciones, los hashtags, las imágenes, los vídeos, los enlaces, el uso de preguntas, las reacciones, las veces que la publicación fue compartida y los comentarios efectuados por la marca y por sus seguidores.

Tal y como proponen Wimmer y Dominick (1996, pp. 184-185), para aumentar la fiabilidad de la ficha de análisis, se definieron al máximo los límites de las categorías, se adiestró a los codificadores y se realizó un ensayo previo. Con referencia a la validez, se puede destacar que las variables empleadas en el protocolo de codificación provienen de ampliar y adaptar estudios previos. Específicamente, esta investigación parte de los principios para integrar el diálogo en internet indicados por Kent \& Taylor (1998), principios que fueron estudiados posteriormente por la academia (García, Miquel-Segarra y Navarro-Beltra, 2018; Kent, Taylor \& White, 2003; Rybalko \& Seltzer, 2010; Taylor, Kent \& White, 2001).

Finalmente, y con el propósito de examinar la información recolectada, se utilizó el programa informático SPSS. En concreto, para describir las variables se utilizaron descriptivos, gráficos de líneas y de barras, frecuencias, tablas de respuesta múltiple y tablas de contingencia. A su vez, para conocer la asociación entre variables, se recurrió al test chi cuadrado de Pearson cuando la variable dependiente era cualitativa y al análisis de la varianza (Anova) cuando la variable dependiente era cuantitativa. En ambos casos, se consideró que las diferencias eran estadísticamente significativas cuando $\mathrm{p}<0,05$. 


\section{Resultados}

\section{Características de las publicaciones}

Como se ha comentado, el $55 \%$ de las publicaciones son realizadas por marcas de moda rápida, en concreto, el 40,3 \% son efectuadas por Zara y el 14,7 \% por H\&M. Por su parte, las empresas de lujo poseen el $45 \%$ de los post, de manera que Hugo Boss cuenta con el 33,3 \% y Ralph Lauren con el $11,7 \%$.

Se podría afirmar que las organizaciones examinadas no suelen utilizar Facebook con asiduidad, ya que Zara posee una mayor frecuencia de publicación y cuenta con una media diaria de 1,09 posts. Seguidamente se puede observar a Hugo Boss con 0,9 publicaciones diarias, y a gran distancia aparecen H\&M y Ralph Lauren con 0,40 y 0,32, respectivamente. Esta situación evidencia que no existe consenso entre las marcas de moda rápida y las de lujo al observar la frecuencia de publicación, pues las dos empresas que más utilizan la red social analizada son Zara (fast fashion) y Hugo Boss (organización de lujo). Además, estos datos parecen evidenciar la falta de interés de las instituciones estudiadas por comunicarse e interactuar con sus públicas a través de Facebook, una herramienta de comunicación digital que permite la bidireccionalidad.

Con referencia a la fecha de publicación, y como se puede observar en la figura 1 , cabe señalar que las marcas de moda rápida suelen ser especialmente activas en marzo $(26,8 \%$ de los posts realizados por este tipo de empresas) y en mayo (19,3\%), de esta forma casi la mitad de las publicaciones encontradas en estos meses pertenecen a Zara $(44,9$ y $46,7 \%$, respectivamente). Además, el sector fast fashion no suele estar activo en enero (4,5\%), de hecho, Hugo Boss, que es considerada como una organización de lujo, es la que más posts realiza ese mes (58,8 \% de las publicaciones de enero).

Por su parte, las marcas de lujo en general prefieren publicar en febrero (25,5\% de los posts efectuados por estas empresas), de esta forma Hugo Boss cuenta con el 36,6 \% de todas publicaciones realizadas ese mes y Ralph Lauren posee el 18,8 \%. Al contario de lo que ocurre con las orga- 
nizaciones de moda rápida, mayo es el periodo menos utilizado por la industria del lujo (10,5\%). Cabe destacar que las diferencias halladas en los meses de publicación en función del tipo de marca son estadísticamente significativas $\left(\mathrm{x}^{2}=39,137, \mathrm{p}=0,000\right)$.

\section{Figura 1. Mes en el que se realiza la publicación por tipo de marca.}

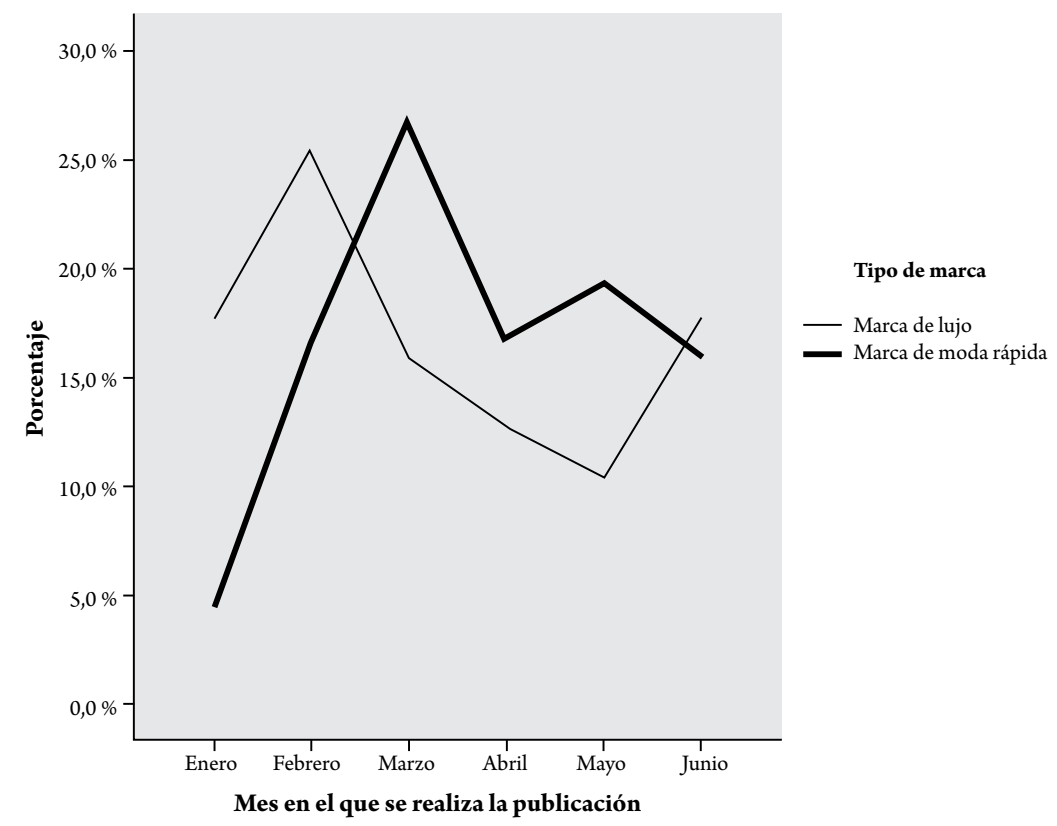

Fuente: elaboración propia.

A diferencia de lo que ocurre en el caso anterior, parece que sí existe consenso entre el tipo de marca y el día de la semana en el que se realiza la publicación, ya que no se producen desemejanzas $\left(x^{2}=1,987 ; p=0,921\right)$. De esta forma, los jueves son los días más prolíficos, seguido de los viernes y de los lunes $(25,17,3$ y $15 \%$, respectivamente, del total de posts elaborados por las organizaciones de lujo y 26, 19,7 y 12,6 \% de los de moda rápida). Además, no se suelen realizar publicaciones los sábados (6,4\% de los posts realizados por las empresas de lujo y $6,7 \%$ de los efectuados por el sector fast fashion). Por tanto, y como se puede observar en la figura 2, las organizaciones analizadas no suelen prestar atención a Facebook los fines de semana, ya que prefieren los últimos días de diario. 
Tampoco se producen diferencias significativas al examinar el tipo de marca y el día del mes en el que se efectúa la publicación $\left(x^{2}=23,716\right.$; $\mathrm{p}=0,785)$. Así, el día en el que se realizan más post es el $16(6,8 \%$ del total de las publicaciones elaboradas por las empresas de lujo y $7,4 \%$ de las de moda rápida).

\section{Figura 2. Día de la semana en el que se realiza la publicación por tipo de marca.}

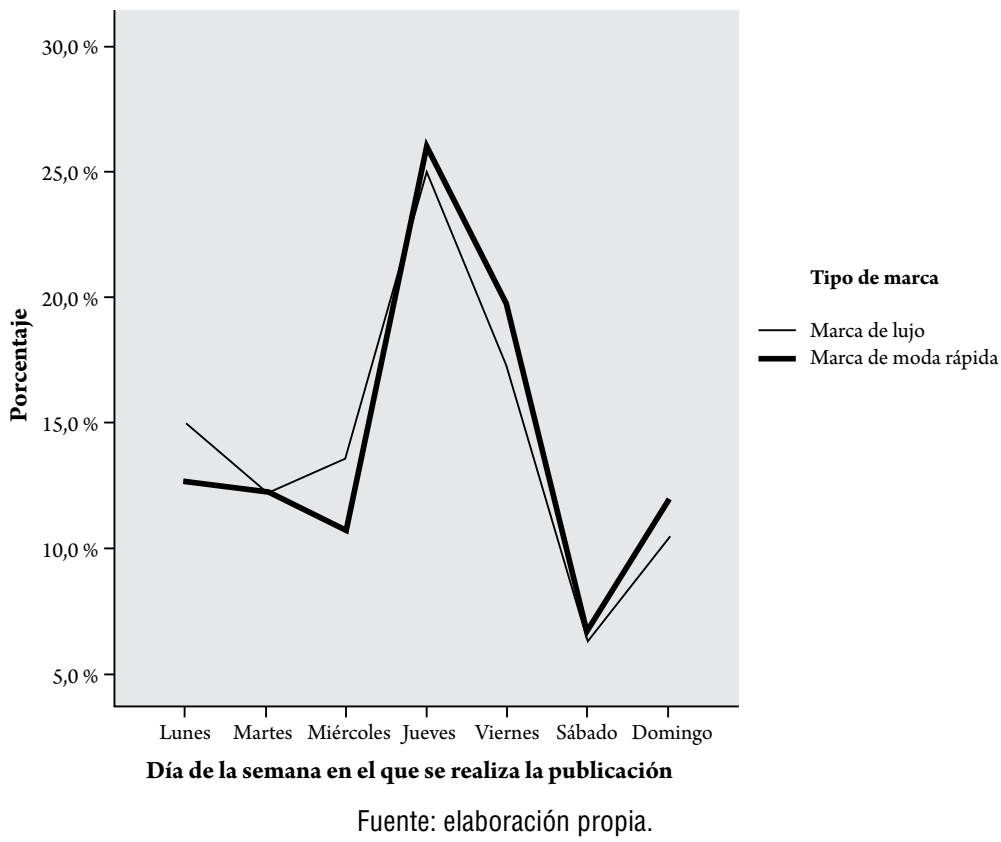

Con referencia al idioma, cabe destacar que las empresas examinadas realizan sus publicaciones principalmente en inglés (96,8\% de los posts efectuados por las organizaciones de lujo y $95,5 \%$ de las catalogadas como fast fashion), de manera que no se producen diferencias estadísticamente significativas entre el tipo de marca $\left(x^{2}=8,292 ; p=0,505\right)$. De esta forma, se evidencia la preferencia que poseen las organizaciones de moda hacia el inglés para comunicarse con un público internacional que presumiblemente posee diversas lenguas maternas.

Pese a estas similitudes, cabe señalar que las instituciones de moda rápida utilizan una mayor variedad de idiomas al emplear en el 2,8\% de 
los posts otras lenguas. En concreto, H\&M utiliza el ruso y Zara el tailandés, el estonio, el lituano, el búlgaro, el turco y el griego. Sin embargo, el español es el único otro idioma que emplean las empresas de lujo (0,9\%) y solo lo utiliza Hugo Boss. En este sentido, no se puede olvidar que también se han encontrado 10 publicaciones sin texto como tal ( $2,3 \%$ para las marcas de lujo y $1,9 \%$ para las de moda rápida), aunque cabe destacar que en algunos de estos casos se ha podido observar texto escrito sobre las imágenes, principalmente en inglés.

\section{Contenido}

Con referencia al uso de menciones, cabe destacar que se producen diferencias estadísticamente significativas en función de su utilización $\left(\mathrm{x}^{2}=68,649\right.$; $\mathrm{p}=0,000$ ). Así, se pueden observar menciones en el 33,3\% de las publicaciones realizadas por las organizaciones de lujo, cifra que se reduce al 4,8 $\%$ en el caso de la moda rápida (figura 3). Así, cabe destacar que el 75,9\% de los posts que contienen menciones son de Hugo Boss, el 14,9 \% de H\&M y el 9,2 \% de Ralph Lauren, ya que Zara no recurre a esta forma de comunicación en ninguna ocasión. El número de menciones empleadas por post también muestra diferencias significativas $(F=63,077$; sig. $=0,000)$. En concreto, las marcas de lujo poseen una media de 0,55 menciones por publicación (con un mínimo de 0 y un máximo de 7); sin embargo, al considerar a las organizaciones de moda rápida, este valor disminuye a 0,05 (con un mínimo de 0 y un máximo de 1 ). Aunque la mayoría de las menciones únicamente aparecen una vez, cabe destacar el caso de Style Scrapbook que se puede observar en dos y los de The Weeknd, TheWeeknd y Zara Larsson que se muestran en tres ocasiones, todas estas menciones pertenecen al sector fast fashion y, en concreto, a H\&M.

Por su parte, no existen diferencias con referencia al uso de hashtags $\left(\mathrm{x}^{2}=3,427 ; \mathrm{p}=0,064\right)$, ya que las empresas de lujo los incluyen en el $43,6 \%$ de sus publicaciones y las del sector fast fashion en el $52 \%$ (figura 3 ). De esta forma, el 35,2 \% de los posts que incluyen hashtags son de Zara, el 24,6\% de Hugo Boss, el 24,2 \% de H\&M y el 16,1 \% de Ralph Lauren. No obstante, sí se pueden encontrar desemejanzas en la cantidad de hashtags empleados por publicación $(\mathrm{F}=5,677$; sig. $=0,018)$, de manera que las organizaciones 
de lujo poseen una media de 0,65 por post (con un mínimo de 0 y un máximo de 8) y las empresas de moda rápida cuentan con una media de 0,87 (con un mínimo de 0 y un máximo de 4 ). En este sentido, cabe señalar que el hashtag más utilizado es \#HM, pues se puede observar en 39 ocasiones.

Es habitual que las marcas examinadas incluyan imágenes en sus posts, de manera que no se producen diferencias estadísticamente significativas en su utilización en función del tipo de institución $\left(x^{2}=1,186 ; p=0,276\right)$. A pesar de estas similitudes, parece relevante señalar que las empresas pertenecientes al sector fast fashion recurren a las imágenes con mayor asiduidad que aquellas que son catalogadas como organizaciones de lujo $(76,6 \%$ de los posts frente a 72,3 \%) (figura 3). De esta forma, el $43 \%$ de las publicaciones que contienen imágenes pertenecen a Zara, el $34,8 \%$ a Hugo Boss, el $13,4 \%$ a H\&M y el 8,8 \% a Ralph Lauren. El número de imágenes utilizadas por post tampoco muestra diferencias $(\mathrm{F}=3,757$; sig. $=0,053)$. Así, las organizaciones de moda rápida poseen una media de 1,79 (con un mínimo de 0 y un máximo de 22), valor que aumenta a 2,35 (con un mínimo de 0 y un máximo de 34) en el caso de las empresas de lujo.

Al considerar el contenido de estos elementos gráficos, cabe destacar que lo más habitual es encontrar imágenes sobre productos de la marca, especialmente en los posts de H\&M y Zara. Sin embargo, al examinar las empresas de lujo, destaca la existencia de una mayor variedad, pues, aunque predominan las imágenes sobre productos, también se muestran eventos con cierta frecuencia en el caso de Ralhp Lauren y deportistas y personajes famosos en el de Hugo Boss. Por tanto, se puede observar cómo las marcas de moda rápida y las de lujo están utilizando una estrategia diferente en relación con el contenido de sus imágenes.

Con referencia a los vídeos, destaca que las organizaciones de lujo los utilizan en el $27,7 \%$ de sus posts, mientras que el sector fast fashion los emplea en el 23,4\% (sin diferencias significativas, $\mathrm{x}^{2}=1,186 ; \mathrm{p}=0,276$ ) (figura 3). En concreto, el $32,3 \%$ de las publicaciones que contienen vídeos son efectuadas por Zara, el $29 \%$ por Hugo Boss, el $20,2 \%$ por Ralph Lauren y el $18,5 \%$ por H\&M. Tampoco se producen desemejanzas al considerar el número de vídeos $(\mathrm{F}=1,184 ;$ sig. $=0,277)$, ya que las marcas de lujo poseen 
una media de 0,28 por publicación y las de moda rápida de 0,23 ; cabe señalar que las empresas examinadas incluyen como máximo un vídeo por post.

En este sentido, las cuatro organizaciones analizadas prefieren centrar el contenido de sus vídeos en sus productos. Sin embargo, destaca que Hugo Boss también suele mostrar a personas famosas o a deportistas patrocinados, y que H\&M además recurre a personajes que colaboran con la marca, como la cantante Zara Larsson que ha creado colecciones para esta.

Por su parte, las empresas de moda rápida utilizan enlaces en el 85,5\% de sus publicaciones y las marcas de lujo los incluyen en el 55,9\%, de manera que estas diferencias son estadísticamente significativas $\left(\mathrm{x}^{2}=52,789\right.$; $\mathrm{p}=0,000)$. Así, el 51,6 \% de los posts que contienen enlaces son realizados por Zara, el 30,6 \% por Hugo Boss, el 13,6 \% por H\&M y el 4,2 \% por Ralph Lauren (figura 3). El número de enlaces por publicación también muestra desemejanzas $(F=46,043$; sig. $=0,000)$, pues las organizaciones de lujo poseen una media de 0,58 , dato que aumenta a 0,86 en el caso del sector fast fashion (con un mínimo de 0 y un máximo de 2 para ambos tipos de marca).

\section{Figura 3. Contenido existente en las publicaciones en función del tipo de marca.}

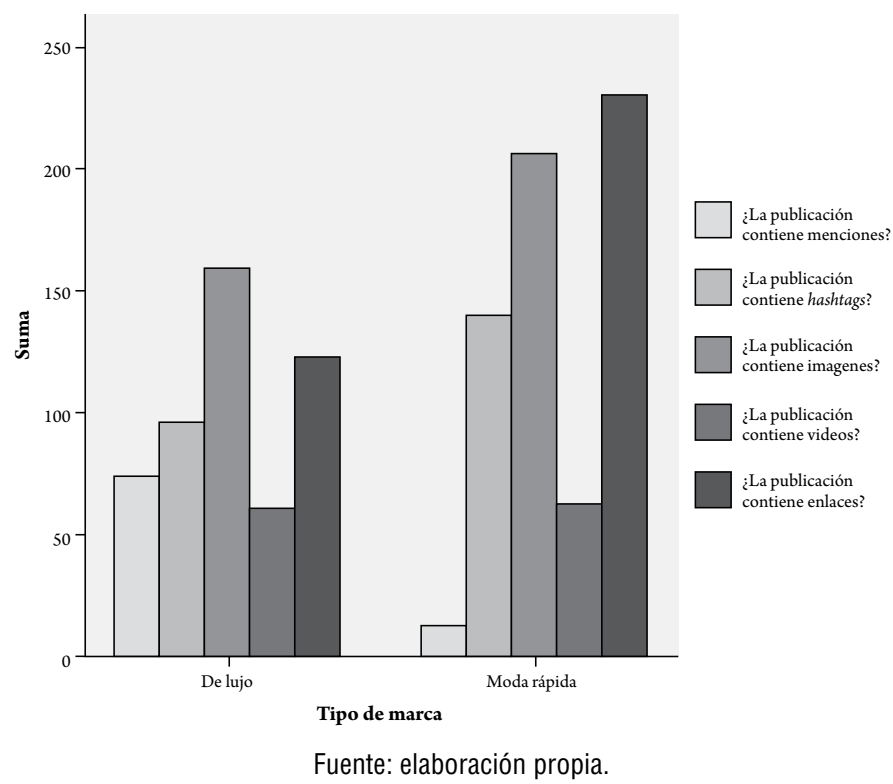


Lo más habitual es que los enlaces encontrados redirijan a los usuarios a un sitio web (95,3 \% de los casos para las empresas de lujo y 99,6 \% para las de moda rápida). Sin embargo, aunque en escasas ocasiones los dos tipos de organizaciones también incluyen links a Facebook $(0,8 \%$ de las de lujo y $0,4 \%$ de las de fast fashion). Además, cabe destacar que las marcas de lujo son las únicas que incorporan otro tipo de enlaces, de manera que redirigen a Instagram ( $1,6 \%)$, a medios de comunicación online $(1,6 \%)$ y a Dalymotion $(0,8 \%)$. A su vez, solo este tipo de organizaciones, y en concreto Hugo Boss, usan enlaces externos, es decir, que llevan a los usuarios a sitios web no relacionados con la empresa ( $3,1 \%$ de sus links), aunque no se puede olvidar que la mayoría son corporativos $(96,9 \%)$. Sin embargo, las marcas de moda rápida solo recurren a enlaces corporativos.

\section{Interacciones}

Al considerar el número total de reacciones que los seguidores incluyen en las publicaciones, cabe destacar que no se producen diferencias entre los tipos de marcas $(F=0,145$, sig. $=0,704)$. De esta forma, las organizaciones de lujo poseen una media de 2440,71 reacciones por post (mínimo 22; máximo 27950 ), cifra que se reduce a 2392,71 en el caso de las empresas de moda rápida (mínimo 56; máximo 4586). Sin embargo, hay algunos botones de reacción específicos que sí producen desemejanzas, a saber: "Me asombra" $(\mathrm{F}=13,662, \mathrm{p}=0,000)$, "Me entristece" ( $\mathrm{F}=8,947 ; \mathrm{p}=0,003)$, "Me enfada" $(F=12,117 ; p=0,001) y$ “Me enorgullece" $(F=5,396$, sig. $=0,021)$. Así, la media de las instituciones de lujo es superior a la del sector fast fashion en los dos primeros botones e inferior en el resto (tablas 1 y 2 ). Por tanto, se trata de dos reacciones positivas y dos negativas para cada tipo de marca, de manera que se podría afirmar que las organizaciones de moda rápida y las de lujo despiertan el mismo tipo de emociones.

\section{Tabla 1. Número de reacciones en función del tipo de marca}

\begin{tabular}{|c|c|c|c|c|c|c|c|c|c|}
\hline \multicolumn{10}{|c|}{ Descriptivos } \\
\hline \multirow{2}{*}{ Reacción } & \multirow{2}{*}{$\begin{array}{l}\text { Tipo de } \\
\text { marca }\end{array}$} & \multirow{2}{*}{$\mathbf{N}$} & \multirow{2}{*}{ Media } & \multirow{2}{*}{$\begin{array}{c}\text { Desviación } \\
\text { estándar }\end{array}$} & \multirow{2}{*}{$\begin{array}{c}\text { Error } \\
\text { estándar }\end{array}$} & \multicolumn{2}{|c|}{$\begin{array}{l}95 \% \text { del intervalo de } \\
\text { confianza para la media }\end{array}$} & \multirow{2}{*}{ Mínimo } & \multirow{2}{*}{ Máximo } \\
\hline & & & & & & $\begin{array}{c}\text { Límite } \\
\text { inferior }\end{array}$ & $\begin{array}{c}\text { Límite } \\
\text { superior }\end{array}$ & & \\
\hline \multirow{3}{*}{$\begin{array}{l}\text { Número total } \\
\text { de reacciones }\end{array}$} & Lujo & 220 & 2440,71 & 3411,447 & 230,000 & 1987,42 & 2894,01 & 22 & 31244 \\
\hline & Fast fashion & 269 & 2353,45 & 1438,132 & 87,684 & 2180,81 & 2526,09 & 56 & 7486 \\
\hline & Total & 489 & 2392,71 & 2522,002 & 114,049 & 2168,62 & 2616,80 & 22 & 31244 \\
\hline
\end{tabular}




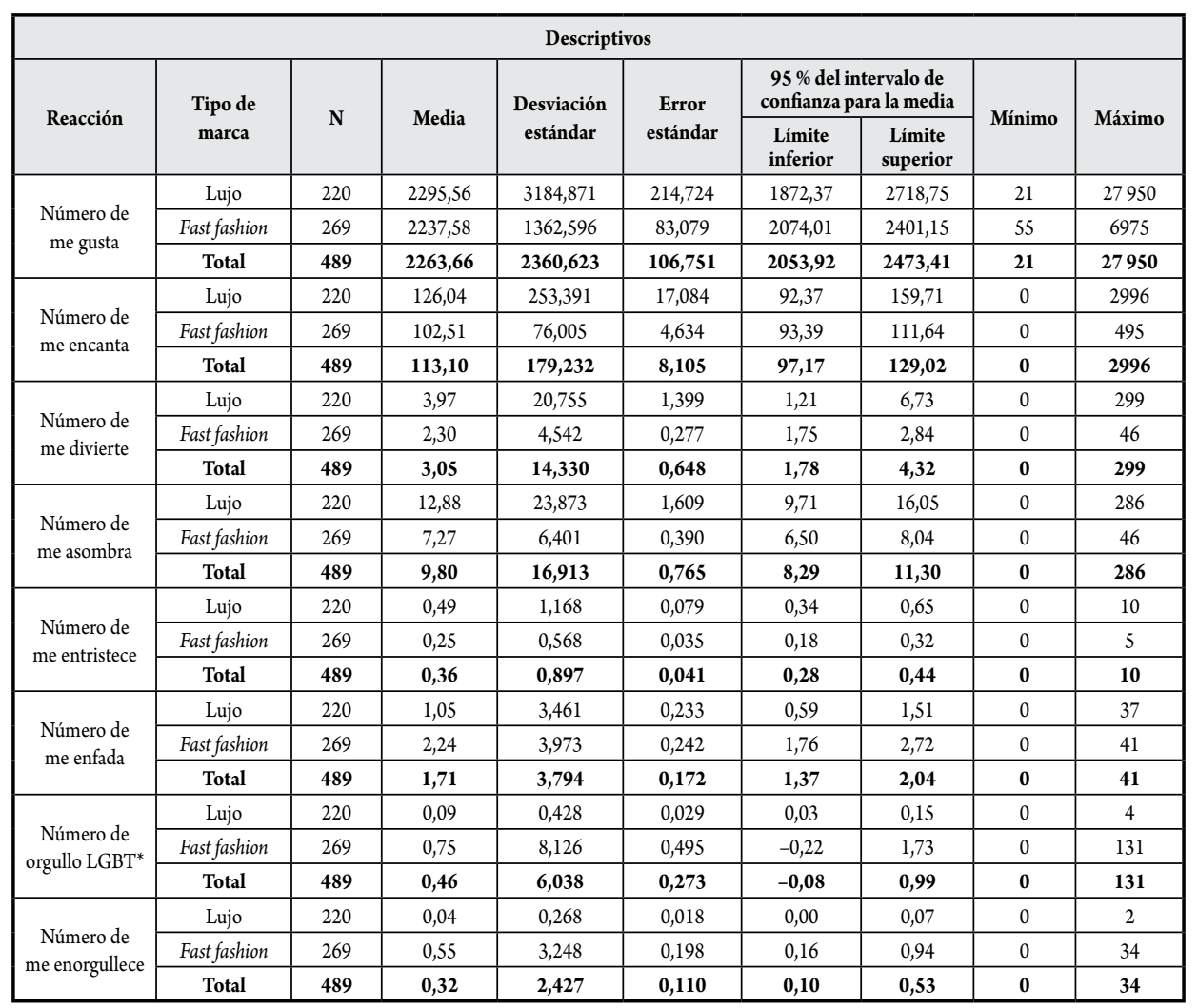

* Esta es una opción temporal que debe activar el usuario y que no aparece por defecto en la botonería originaria de Facebook.

Fuente: elaboración propia.

\section{Tabla 2. Anova calculado para el número de reacciones en función del tipo de marca}

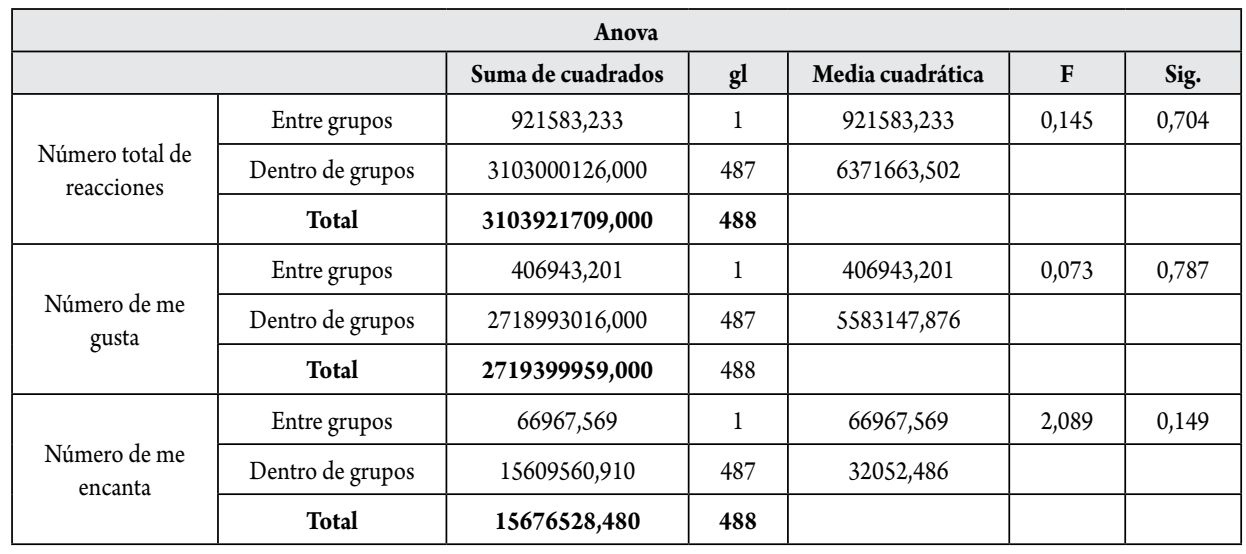




\begin{tabular}{|c|c|c|c|c|c|c|}
\hline \multicolumn{7}{|c|}{ Anova } \\
\hline & & Suma de cuadrados & gl & Media cuadrática & $\mathbf{F}$ & Sig. \\
\hline \multirow{3}{*}{$\begin{array}{l}\text { Número de me } \\
\text { divierte }\end{array}$} & Entre grupos & 337,837 & 1 & 337,837 & 1,647 & 0,200 \\
\hline & Dentro de grupos & 99870,985 & 487 & 205,074 & & \\
\hline & Total & 100208,822 & 488 & & & \\
\hline \multirow{3}{*}{$\begin{array}{l}\text { Número de me } \\
\text { asombra }\end{array}$} & Entre grupos & 3809,433 & 1 & 3809,433 & 13,662 & 0,000 \\
\hline & Dentro de grupos & 135790,117 & 487 & 278,830 & & \\
\hline & Total & 139599,550 & 488 & & & \\
\hline \multirow{3}{*}{$\begin{array}{l}\text { Número de me } \\
\text { entristece }\end{array}$} & Entre grupos & 7,078 & 1 & 7,078 & 8,947 & 0,003 \\
\hline & Dentro de grupos & 385,294 & 487 & 0,791 & & \\
\hline & Total & 392,372 & 488 & & & \\
\hline \multirow{3}{*}{$\begin{array}{l}\text { Número de me } \\
\text { enfada }\end{array}$} & Entre grupos & 170,543 & 1 & 170,543 & 12,117 & 0,001 \\
\hline & Dentro de grupos & 6854,639 & 487 & 14,075 & & \\
\hline & Total & 7025,182 & 488 & & & \\
\hline \multirow{3}{*}{$\begin{array}{l}\text { Número de orgullo } \\
\text { LGBT }^{*}\end{array}$} & Entre grupos & 53,316 & 1 & 53,316 & 1,464 & 0,227 \\
\hline & Dentro de grupos & 17735,989 & 487 & 36,419 & & \\
\hline & Total & 17789,305 & 488 & & & \\
\hline \multirow{3}{*}{$\begin{array}{l}\text { Número de me } \\
\text { enorgullece }\end{array}$} & Entre grupos & 31,491 & 1 & 31,491 & 5,396 & 0,021 \\
\hline & Dentro de grupos & 2842,378 & 487 & 5,837 & & \\
\hline & Total & 2873,869 & 488 & & & \\
\hline
\end{tabular}

* Esta es una opción temporal que debe activar el usuario y que no aparece por defecto en la botonería originaria de Facebook.

Fuente: elaboración propia.

También existen diferencias al considerar el número de veces que el contenido fue compartido por los usuarios $(\mathrm{F}=41,789$, sig. $=0,000)$. Así, las publicaciones realizadas por las marcas de lujo poseen una media de 145,62 (con un mínimo 0 y un máximo de 2203), mientras que las empresas de moda rápida cuentan con una media de 50,83 (con un mínimo de 0 y un máximo de 432). Quizá, los contenidos creados por las instituciones de lujo se comparten con mayor asiduidad por la necesidad que poseen algunas personas de demostrar su vinculación con este sector.

Las diferencias halladas entre las marcas de lujo y las de la industria fast fashion son significativas $\left(x^{2}=7,588, p=0,006\right)$, aunque no es habitual que las organizaciones analizadas incluyan preguntas en sus publicaciones con el propósito de fomentar el diálogo con sus seguidores. En concreto, las primeras recurren a esta técnica con mayor frecuencia que las segun- 
das $(6,8 \%$ de los posts frente a $1,9 \%)$ (figura 4$)$, de esta forma, el $70 \%$ de las publicaciones que incluyen preguntas son realizadas por Hugo Boss, el $15 \%$ por H\&M, el $10 \%$ por Zara y el $5 \%$ por Ralph Lauren.

Es habitual que los seguidores interactúen con las organizaciones (sin diferencias estadísticamente significativas por tipo de marca: $x^{2}=2,636$; $p=0,104)$, a pesar de esta situación, ya que el $94,5 \%$ de las publicaciones de las empresas de lujo y el $97,4 \%$ de las catalogadas como moda rápida poseen comentarios por parte de los usuarios (figura 4). De esta forma, el $40,9 \%$ de los posts que tienen comentarios pertenecen a Zara, el 32,1\% a Hugo Boss, el 14,9 \% a H\&M y el 12,1 \% a Ralph Lauren. Sin embargo, sí existen desemejanzas en el número de comentarios obtenidos $(\mathrm{F}=6,460$; sig. $=0,011)$, de manera que las organizaciones de lujo poseen una media de 56,36 por post (mínimo 0 ; máximo 1395) y las de moda rápida de 29,58 (mínimo 0; máximo 180). Al igual que en el caso anterior, tal vez, los usuarios prefieran comentar las publicaciones efectuadas por las marcas de lujo con mayor frecuencia para demostrar su estatus.

Al considerar si las organizaciones responden a los comentarios efectuados por sus seguidores, cabe destacar que las empresas de moda rápida incluyen respuestas en sus propias publicaciones casi en la mitad de los posts $(48,3 \%)$, cifra que se reduce en 31 puntos $(17,3 \%)$ en el caso de las marcas más lujosas (estas diferencias son significativas: $\mathrm{x}^{2}=51,751 ; \mathrm{p}=0,000$ ) (figura 4). Esta situación se produce a pesar de que los seguidores suelen incluir un mayor número de comentarios en los posts realizados por las empresas de lujo. Quizá, este tipo de organizaciones no sientan la necesidad de responder, pues consideren que ser demasiado accesibles puede mermar su imagen de exclusividad. De esta forma, cabe señalar que, del total de posts en los que se pueden observar respuestas por parte de las instituciones, el 67,3 \% pertenecen a Zara, el 22,6 \% a Hugo Boss y el 10,1 \% a H\&M, pues Ralph Lauren no realizada esta actividad en ninguna ocasión. El número de respuestas ofrecidas por las organizaciones también muestra desemejanzas $(F=43,325$; sig. $=0,000)$, ya que las marcas de lujo incluyen una media de 0,33 comentarios por publicación (mínimo 0 , máximo 4) y las de moda rápida de 1,47 (mínimo 0, máximo 15). 


\section{Figura 4. Interacciones en las publicaciones en función del tipo de marca.}

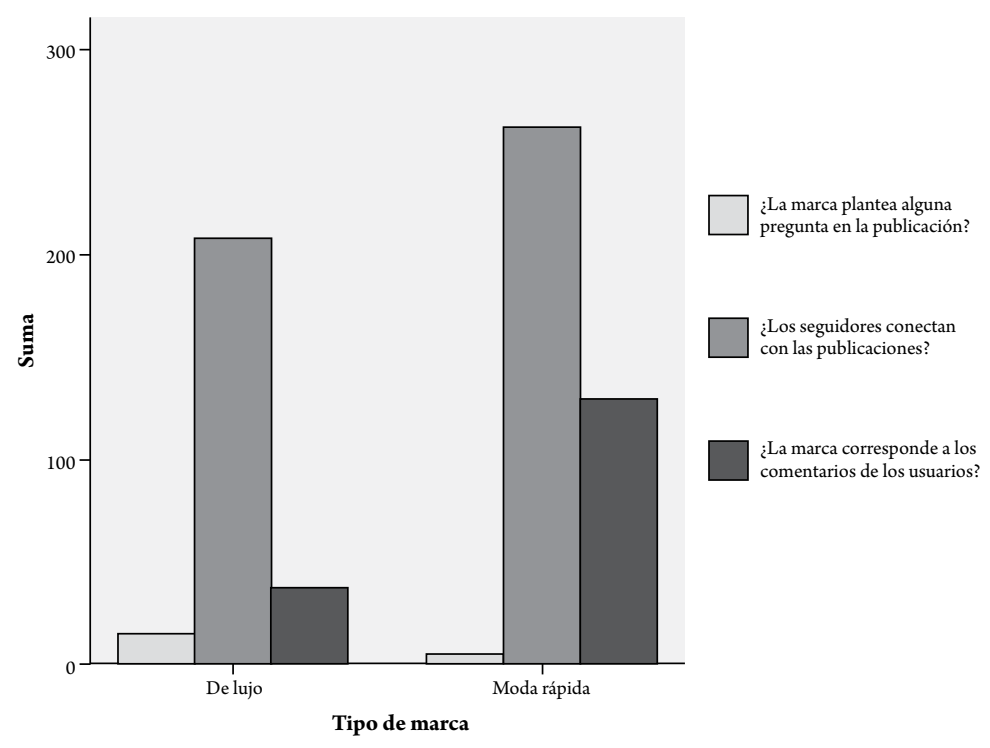

Fuente: elaboración propia.

\section{Discusión y conclusiones}

Como se ha podido observar, la comunicación que realizan las marcas de moda rápida y las de lujo a través de Facebook difiere en algunos aspectos: utilizan de manera diferente las menciones, los hashtags, los enlaces, etc. Sin embargo, también posee ciertas semejanzas: predomina el uso de la lengua inglesa, las publicaciones se suelen realizar los jueves y a mediados de mes, es habitual encontrar imágenes pero no vídeos, etc.

No obstante, parece especialmente relevante prestar atención a las variables relacionadas directamente con el diálogo y la interacción, ya que las redes sociales se caracterizan por facilitar la comunicación bidireccional (Aced, 2013, p. 153) entre la organización y sus públicos. De esta forma, aunque los seguidores de las marcas de moda estudiadas han mostrado interés en dialogar, se podría considerar que las organizaciones examinadas, especialmente las de moda rápida, no están explotando las posibilidades de interacción que ofrece Facebook al no introducir de manera habitual preguntas en sus publicaciones, estrategia que invita directamente a los se- 
guidores a ofrecer una respuesta (Huertas, Setó-Pàmies y Miguel-González, 2015, pp. 17-18).

Por su parte, aunque no existen diferencias en el número total de reacciones obtenidas ni en la cantidad de publicaciones que cuentan con comentarios de los usuarios en función del tipo de marca, el resto de indicadores de repercusión (contenido compartido y número de comentarios realizados por los seguidores) parece favorecer a las organizaciones de lujo. Esta circunstancia se produce a pesar de que estas empresas no suelen responder a los comentarios de sus usuarios. Quizá, esta situación se podría explicar al considerar que ciertas personas tratan de relacionarse con las marcas de lujo con la intención de fomentar una imagen personal que se asocie con este tipo de productos (Muñoz, Reyes y Orrego, 2015, p. 47). Las marcas ya no sirven únicamente para identificar y reconocer el producto, ahora también son símbolo de pertenencia a un estilo de vida, a un grupo, de encarnación de una idea, de un estatus o como autoimagen de su consumidor o usuario (Costa, 2007, p. 151).

Así, poseer artículos de lujo tradicionalmente se ha relacionado con "la diferenciación del individuo dentro de los distintos estratos sociales y periodos históricos" (Liberal y Sierra, 2013, p. 905). Por tanto, se podría afirmar que el lujo no es un fin en sí mismo (algo que se quiere tener), es más bien un medio (algo que se utiliza para aparentar ser alguien que no se es en realidad) (Hurtado, 2015).

A pesar del potencial comunicativo que ofrece internet, muchas organizaciones (entre las que se encuentran las relacionadas con el sector de la moda) todavía no están aprovechando al máximo sus oportunidades y siguen utilizando una comunicación unidireccional (Aced y Lazuela, 2016, pp. 136-137). De esta forma, se podría afirmar que todavía no se ha aceptado el aspecto dialógico de las redes sociales (Shen \& Bissell, 2013) en general, ni de Facebook en particular (McCorkindale, 2010).

Por tanto, no es suficiente con estar presente en las redes sociales, sino que es necesario aprovechar el potencial dialógico que estas plataformas de comunicación ofrecen. De hecho, la creación de perfiles en las re- 
des sociales que se basan únicamente en la presencia y que no fomentan la participación provocan un descontento mayor que la ausencia del perfil, ya que los beneficios de estar presente en las plataformas 2.0 se empiezan a conseguir cuando se elimina la comunicación unidireccional y empieza a aparecer la retroalimentación (Túñez y Sixto, 2011). Así, para establecer vínculos con los usuarios en las redes sociales, se recomienda fomentar el diálogo, leer los comentarios de los seguidores, interactuar con ellos, prestarles atención, escucharlos y responder a sus necesidades (Palazón, Sicilia y Delgado, 2014, pp. 33-34).

Finalmente, cabe señalar como la principal limitación de este estudio haber recurrido únicamente a la metodología cuantitativa. Así, una de las líneas de investigación más destacadas que surge con la realización de esta investigación se basa en ampliar el conocimiento académico sobre el tema de estudio con la utilización de la triangulación metodológica. Por tanto, en futuros trabajos sería interesante recurrir tanto a la metodología cuantitativa como a la cualitativa para examinar los discursos que las marcas de moda realizan a través de diversas plataformas digitales.

\section{Referencias}

Aced, C. (2013). Relaciones públicas 2.0: cómo gestionar la comunicación corporativa en el entorno digital. Barcelona, España: UOC.

Aced, C. y Lalueza, F. (2016). ¿Qué contenidos publican las empresas en los medios sociales? Análisis crítico del discurso de las compañías del IBEX 35 y del Fortune 500 en blogs corporativos, Facebook y Twitter. Revista Internacional de Relaciones Públicas, 6(11), 135154.http://revistarelacionespublicas.uma.es/index.php/revrrpp/ article/view/403

Acosta, G. L. (2012). Gestión de pasiones y polarización en las redes sociales: un análisis del aplicativo Grupos en Facebook. Discurso y Sociedad, 6(4), 684-719.http://www.dissoc.org/ediciones/v06n04/ DS6(4)Acosta.pdf 
Blum, H., Flores Vllacrés, E., Vallejo de la Torre, C. y Sánchez Parrales, C. E. (2016). Negocios internacionales. Revista Caribeña de Ciencias Sociales. http://www.eumed.net/rev/caribe/2016/12/negocios.html

Castelló, A. (2012). La comunicación de los portales de descuentos y cupones a través de Facebook. AdComunica: Revista de Estrategias, Tendencias e Innovación en Comunicación, 3, 65-86. http://doi. org/10.6035/2174-0992.2012.3.5

Cheung, F. S. \& Leung, W. F. (2016). Facebook users' habits in getting commercial information: A study on Hong Kong students. Economics, Management, and Financial Markets, 11(3), 56-71. https:// addletonacademicpublishers.com/732-economics-managementand-financial-markets/volume-11-3-2016/2769-facebook-usershabits-in-getting-commercial-information-a-study-on-hongkong-students

Costa, J. (2007). La imagen de marca: un fenómeno social. Barcelona, España: Paidós.

Ertemel, A. V. \& Ammoura, A. (2016). The role of social media advertising in consumer buying behavior. International Journal of Commerce and Finance, 2(1), 81-89. https://papers.ssrn.com/sol3/papers. cfm?abstract_id $=3350965$

Escobar, A. (2016). The impact of the digital revolution in the development of market and communication strategies for the luxury sector (fashion luxury). Central European Business Review, 5(2), 17-36. https://www.ceeol.com/search/article-detail?id=673111

Fernández, E. y Díaz-Campo, J. (2014). Los canales temáticos infantiles y juveniles en Facebook: análisis de los perfiles de Disney Channel, Boing y Neox. Comunicación y Hombre, 10, 179-194. https://doi. org/10.32466/eufv-cyh.2014.10.164.179-194 
Fung, Y.-N. \& Choi, T.-M. (2018). Product development process of an international luxury fashion Brand: Implications to Hong Kong fashion trading and manufacturing companies. En P.-S. Chow, C.-H. Chiu, A. C. Y. Yip \& A. K. Y. Tang (Eds.), Contemporary case studies on fashion production marketing and operations. (pp. 27-42). Singapur: Springer Nature.

García, L. (2015, diciembre 2). Guía de supervivencia para entender el calendario de desfiles. Harper's Bazaar. https://www.harpersbazaar. $\mathrm{com} / \mathrm{es} / \mathrm{moda} /$ noticias-moda/a158316/entender-calendariodesfiles-semanas-moda/

García, J., Fernández, J., Durán, J. y Vélez, L. (2015). La actividad en las redes sociales: un estudio de caso en la industria del fitness. Retos: Nuevas Tendencias en Educación Física, Deporte y Recreación, 28, 4449. https://idus.us.es/handle/11441/59900?

García, D. (2010). Redes sociales: posibilidades de Facebook para las bibliotecas públicas. BiD: Textos Universitaris de Biblioteconomia i Documentació, 24. http://bid.ub.edu/24/pdf/garcia2.pdf

García, I, Miquel-Segarra, S. y Navarro-Beltrá, M. (2018). El uso de Twitter en las marcas de moda: marcas de lujo frente a marcas low-cost. Cuadernos.info, 42, 55-70. https://doi.org/10.7764/cdi.42.1349

González, Z. y Plaza, N. (2017). Estrategias de marketing digital en el sector de la moda de lujo: interacciones y redes sociales como herramienta necesaria. Hipertex.net: Revista Académica sobre Documentación Digital y Comunicación Interactiva, 15, 17-27. https:// doi.org/10.2436/20.8050.01.42

Huertas, A, Setó-Pàmies, D. y Miguel-González, M. I. (2015). Comunicación de destinos turísticos a través de los medios sociales. El Profesional de la Información, 24(115-21). https://doi.org/10.3145/ epi.2015.ene.02 
Hurtado, J. M. (2015). El lujo como construcción ontológica ambivalente. Études caribéennes, 30. https://doi.org/10.4000/etudescaribeennes. 7315

Interbrand. (2015). The Best 100 Brands 2015. https://www.interbrand. com/best-brands/best-global-brands/2015/ranking/

Kent, M. L. \& Taylor, M. (1998). Building dialogic relationships through the World Wide Web. Public Relations Review, 24(3), 321-334. https://doi.org/10.1016/S0363-8111(99)80143-X

Kent, M. L., Taylor, M. \& White, W. J. (2003). The relationship between web site design and organizational responsiveness to stakeholders. Public Relations Review, 29(1), 63-77. https://doi.org/10.1016/ S0363-8111(02)00194-7

Liberal, S. y Sierra, J. (2016). El consumo de marcas de lujo: significado y hábitos de compra. Opción, 32(7), 938-958. https://produccioncientificaluz.org/index.php/opcion/article/view/21515

Lipovetsky, G. (2009). El imperio de lo efímero: la moda y su destino en las sociedades modernas. Barcelona, España: Anagrama.

López, M. C. (2012). El impacto ambiental del fash fasion pronta moda. Arquetipo, 4, 71-79. http://revistas.ucp.edu.co/index.php/arquetipo/article/view/1088

Manikonda, L., Venkatesan, R., Kambhampati, S. \& Li, B. (2016). Trending chic: Analyzing the influence of social media on fashion brands. arXiv. https://arxiv.org/abs/1512.01174

Marauri, I, Pérez,J.Á.y Rodríguez, M. del M. (2015). La búsqueda de la comunidad de marca en las redes sociales: los casos de Telepizza, Vips y Burger King. Trípodos, 37, 133-149. http://www.tripodos.com/ index.php/Facultat_Comunicacio_Blanquerna/article/view/256 
Matthiesen, I. M. \& Phau, I. (2010). Brand image inconsistencies of luxury fashion brands: A buyer-seller Exchange situation model of Hugo Boss Australia. Journal of Fashion Marketing and Management: An International Journal, 14(2), 202-218. https://doi. org/10.1108/13612021011046066

McCorkindale, T. (2010). Can you see the writing on my wall? A content analysis of the Fortune 50's Facebook social networking sites. $\mathrm{Pu}$ blic Relations Journal, 4(3), 1-13. http://citeseerx.ist.psu.edu/ viewdoc/download?doi=10.1.1.470.6602\&rep=rep1\&type=pdf

Morales, A. M. y Morales Rodríguez, F. M. (2017). Las TIC en el mundo de la moda: reconocimiento de marca a través de redes sociales. En J. Ruiz-Palmero, J. Sánchez-Rodríguez y E. Sánchez-Rivas (Eds.), Innovación docente y uso de las TIC en educación. Málaga: UMA Editorial. http://www.enriquesanchezrivas.es/congresotic/archivos/AplicWeb_20/MoralesRodriguez.pdf

Muñoz, M., Reyes, F. y Orrego, J. (2015). Una mirada de los aspectos económicos, simbólicos y emocionales como parte de un conjunto de prácticas que determinan experiencias de consumo de bienes de lujo. Revista Academia \& Negocios, 1(1), 45-56. https:// papers. ssrn.com/sol3/papers.cfm?abstract_id=2774524

Nataur, L. (2017, septiembre 25). Facebook alcanza los 2.000 millones de usuarios conectados al mes. $A B C$. https://www.abc.es/tecnologia/redes/abci-facebook-alcanza-2000-millones-usuarios-conectados-201706272009_noticia.html

Nunes, M. \& Silveira, G. (2016). Análise das motivações do consumidor de fast-fashion. Raimed: Revista de Administração IMED, 6(1), 5671. https://doi.org/10.18256/2237-7956/raimed.v6n1p56-71

Ormaechea, S. L. \& Sánchez, J. S. (2013). The defining attributes of a luxury brand for consumers. Intangible Capital, 9(3), 903-930. https:// doi.org/10.3926/ic.407 
Palazón, M., Sicilia, M. y Delgado, E. (2014). El papel de las redes sociales como generadoras de "amor a la marca". Universia Business Review, 41, 18-39. https://journals.ucjc.edu/ubr/article/view/897

Pedersen, E. R, Naranjo, D. \& Marshall, G. N. (2017). Recruitment and retention of young adult veteran drinkers using Facebook. PLoS ONE, 12(3), e0172972. https://doi.org/10.1371/journal. pone. 0172972

Phua, J., Jin, S. V. \& Kim, J. J. (2017). Gratifications of using Facebook, Twitter, Instagram, or Snapchat to follow brands: The moderating effect of social comparison, trust, tie strength, and network homophily on brand identification, brand engagement, brand commitment, and membership intention. Telematics and Informatics, 34(1), 412424. https://doi.org/10.1016/j.tele.2016.06.004

Pino, C. del y Castelló-Martínez, A. (2015). La comunicación publicitaria se pone de moda: branded content y fashion films. Revista Mediterránea de Comunicación, 6(1), 105-128. https://doi.org/10.14198/ MEDCOM2015.6.1.07

Reina, J., Fernández, I. y Noguer, Á. (2012). El uso de las redes sociales en las universidades andaluzas: el caso de Facebook y Twitter. Revista Internacional de Relaciones Públicas, 2(4), 123-144. https:// doi. org/10.5783/RIRP-4-2012-06-123-144

Remy, N., Catena, M. \& Durand-Servoingt, B. (2015). Digital inside: Get wired for the ultimate luxury experience. Nueva York, EE. UU.: McKinsey \& Company. http://vietnamsupplychain.com/assets/ files/562451c67cbbbDigital_inside_full_PDF.pdf

Rocha, M. V. (2018). Moda e Impressão 3D: um novo paradigma? Revista Electrónica de Direito, 17(3), 106-151. https://doi. org/10.24840/2182-9845_2018-0003_0006 
Rybalko, S. \& Seltzer, T. (2010). Dialogic communication in 140 characters or less: How Fortune 500 companies engage stakeholders using twitter. Public Relations Review, 36(4), 336-341. https://doi. org/10.1016/j.pubrev.2010.08.004

Shen, B. \& Bissell, K. (2013). Social media, social me: A content analysis of companies' use of Facebook. Journal of Promotion Management, 19(5), 629-651. https://doi.org/10.1080/10496491.2013 .829160

Sicard, M. C. (2010). Luxe, mensonges et marketing. París, Francia: Pearson.

Taylor, M., Kent, M. L. \& White, W. J. (2001). How activist organizations are using the internet to build relationships. Public Relations Review, 27(3), 263-284. https://doi.org/10.1016/ S0363-8111(01)00086-8

Toboso, S. (2017). La insostenibilitat del fast fashion. Datatèxtil, 36. https://www.raco.cat/index.php/Datatextil/article/ view/321851/412481

Tongo, R. B. (2017, junio 27). Facebook ya tiene 2.000 millones de usuarios en todo el mundo. Expansión. http://www.expansion.com/ economia-digital/companias/2017/06/27/5952a4ef46163f2c1 48b460b.html

Torres-Briones, C. L., Rojas-Dávila, R. y Cabrera-Jara, C. A. (2017). Análisis de la percepción de los artículos de lujo en jóvenes universitarios. Dominio de las Ciencias, 3(2), 581-598. https://doi.org/10.23857/ dom.cien.pocaip.2017.3.2.esp.581-598

Túñez,J. M. y Sixto, J. (2011). Redes sociales, política y compromiso 2.0: la comunicación de los diputados españoles en Facebook. Revista Latina de Comunicación Social, 66, 210-234.https:// doi.org/10.4185/ RLCS-66-2011-930-210-234 
Tuunainen, V. K. \& Rossi, M. (2002). eBusiness in apparel retailing industrycritical issues. Trabajo presentado en el 10th European Conference on Information Systems (ECIS), Gdansk, Polonia.

Viñarás, M. y Cabezuelo, F. (2012). Claves para la participación y generación de contenido en redes sociales: estudio de caso del $\mathrm{Mu}-$ seo del Prado en Facebook. AdComunica: Revista de Estrategias, Tendencias e Innovación en Comunicación, 3, 87-103. https://doi. org/10.6035/2174-0992.2012.3.6

Wimmer, R. D. y Dominick, J. R. (1996). La investigación científica de los medios de comunicación: una introducción a sus métodos. Barcelona, España: Bosch.

Zambon, A. C. Busichia, G, Torres, L. A. y Galindo Jaramillo, J. F. (2017). Empleo de instrumentos de gestión del conocimiento para comprensión de los patrones de preferencia del consumidor en productos de la cadena de la moda. Perspectivas em Gestão \& Conhecimento, 7, 50-65. https://dialnet.unirioja.es/servlet/ articulo?codigo $=5908260$ 